\title{
Errors Associated to Keratoconus Grading using Systems based on Corneal Power
}

\author{
${ }^{1}$ David P Piñero Llorens, ${ }^{2}$ Vicente Camps, ${ }^{3}$ Esteban Caravaca-Arens
}

\section{ABSTRACT}

Purpose: To analyze and define the possible errors that may be introduced in keratoconus classification when the keratometric corneal power is used in such classification.

Materials and methods: Retrospective study including a total of 44 keratoconus eyes. A comprehensive ophthalmologic examination was performed in all cases, which included a corneal analysis with the Pentacam system (Oculus). Classical keratometric corneal power $\left(P_{k}\right)$, Gaussian corneal power $\left(\mathrm{P}_{\mathrm{C}}^{\text {Gauss }}\right.$ ), True Net Power (TNP) (Gaussian power neglecting the corneal thickness effect), and an adjusted keratometric corneal power $\left(P_{\text {kadj }}\right)$ (keratometric power considering a variable keratometric index) were calculated. All cases included in the study were classified according to five different classification systems: Alió-Shabayek, Amsler-Krumeich, RabinowitzMcDonnell, collaborative longitudinal evaluation of keratoconus (CLEK), and McMahon.

Results: When $\mathrm{P}_{\mathrm{k}}$ and $\mathrm{P}_{\text {kadj }}$ were compared, differences in the type of grading of keratoconus cases was found in $13.6 \%$ of eyes when the Alió-Shabayek or the Amsler-Krumeich systems were used. Likewise, grading differences were observed in $22.7 \%$ of eyes with the Rabinowitz-McDonnell and McMahon classification systems and in $31.8 \%$ of eyes with the CLEK classification system. All reclassified cases using $P_{\text {kadj }}$ were done in a less severe stage, indicating that the use of $P_{k}$ may lead to the classification of a cornea as keratoconus, being normal. In general, the results obtained using $P_{\text {kadj }}, P_{c}^{\text {Gauss }}$ or the TNP were equivalent. Differences between $P_{\text {kadj }}$ and $P_{c}^{\text {Gauss }}$ were within $\pm 0.7 \mathrm{D}$

Conclusion: The use of classical keratometric corneal power may lead to incorrect grading of the severity of keratoconus, with a trend to a more severe grading.

Keywords: Corneal topography, Keratoconus, Pentacam.

How to cite this article: Llorens DPP, Camps V, CaravacaArens E. Errors Associated to Keratoconus Grading using Systems based on Corneal Power. Int J Kerat Ect Cor Dis 2015;4(2):41-46.

Source of support: Nil

Conflict of interest: None

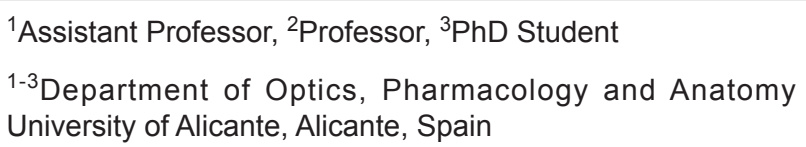

Corresponding Author: David P Piñero Llorens, Assistant Professor, Department of Optics, Pharmacology and Anatomy University of Alicante, Alicante, Spain, Phone: 34965903500 e-mail: david.pinyero@ua.es

\section{INTRODUCTION}

In a previous paper of our research group, theoretical and clinical errors associated to the calculation of central corneal power in keratoconus eyes considering a unique keratometric index $\left(\mathrm{n}_{\mathrm{k}}\right)$ and the anterior corneal radius $\left(\mathrm{r}_{1 \mathrm{c}}\right)$ (keratometric corneal power, $\mathrm{P}_{\mathrm{k}}$ ) were analyzed and compared, using as a reference the Gaussian corneal power $\left(\mathrm{P}_{\mathrm{c}}^{\text {Gauss }}\right)$, which is calculated considering both anterior $\left(r_{1 c}\right)$ and posterior $\left(r_{2 c}\right)$ corneal radii. In the theoretical simulations, an overestimation of $\mathrm{P}_{\mathrm{k}}$ was observed in most of cases, with differences among the Gaussian and keratometric approaches $\left(\Delta \mathrm{P}_{\mathrm{c}}=\mathrm{P}_{\mathrm{k}}-\mathrm{P}_{\mathrm{c}}^{\text {Gauss }}\right)$ ranging from -0.1 to $4.3 \mathrm{D}$, depending on $\mathrm{r}_{1 \mathrm{c}}$ and $\mathrm{r}_{2 \mathrm{c}}$ combinations and the theoretical eye model considered. Clinically, $\mathrm{P}_{\mathrm{k}}$ was always found to overestimate the $\mathrm{P}_{\mathrm{c}}^{\text {Gauss }}$ provided by the topography system in a range between 0.5 and $2.5 \mathrm{D}(\mathrm{p}<0.01)$, with a mean clinical difference $\left(\Delta \mathrm{P}_{\mathrm{c}}\right)$ of $1.48 \mathrm{D}$. According to all these findings, we concluded that the use of a single value of $n_{k}$ for the calculation of corneal power was imprecise in keratoconus and could lead to significant theoretical and clinical errors. ${ }^{1}$ These errors could be reduced to clinically acceptable levels by using an adjusted keratometric index $\left(n_{\text {kadj }}\right)$, with values ranging from 1.3153 to 1.3396 , and derived from a linear expression depending on the $\mathrm{r}_{1 \mathrm{c}}$ value. $^{2}$

Current classification and detection tools for keratoconus are based on different criteria, but most of them still consider the optical power of the cornea as one of the most relevant parameters to consider. ${ }^{3}$ As there is no uniform classification for the severity of keratoconus to date, different approaches have been reported in the literature using a combination of objective and subjective parameters. ${ }^{4-6}$ Likewise, several indices, algorithms, and even neural network approaches based on geometrical and optical properties of the anterior corneal surface have been developed for keratoconus diagnosis and detection. ${ }^{5-7}$ Specifically, indexes and parameters, such as corneal irregularity measurement (CIM), mean toric keratometry (MTK), surface regularity index (SRI), predicted corneal acuity (PCA), surface asymmetry index (SAI), central keratometry (CK) value or the I-S index have been shown to be valuable tools for the diagnosis and even classification of keratoconus., ${ }^{4,8-8-11}$ 
The aim of the current study was to analyze and define the possible errors that may be introduced in keratoconus classification when the keratometric corneal power is used in such classification. Specifically, this analysis was performed using several different types of keratoconus classification systems that are still currently accepted and widely used in clinical practice. ${ }^{6,712-14}$

\section{MATERIALS AND METHODS}

Retrospective study including a total of 44 keratoconus eyes revised at the department of ophthalmology (Oftalmar) of the Medimar International Hospital (Alicante, Spain). The inclusion criterion for the study was the presence of keratoconus using the standard criteria for the diagnosis of this corneal condition: corneal topography revealing an asymmetric bowtie pattern with or without skewed axes and at least one keratoconus sign on slit-lamp examination, such as stromal thinning, conical protrusion of the cornea at the apex, Fleischer ring, Vogt striae or anterior stromal scar. ${ }^{15}$ Exclusion criteria were previous ocular surgery and other active ocular disease. Consent to include clinical information in scientific studies was taken from all patients, following the tenets of the Helsinki declaration. In addition, local ethics committee approval was obtained for this investigation.

A comprehensive ophthalmologic examination was performed in all cases, which included refraction, corrected distance visual acuity (CDVA), slit lamp biomicroscopy, Goldman tonometry, fundus evaluation, and the analysis of the corneal structure by means of a scheimpflug photography-based tomographer, the pentacam system (Oculus Optikgeräte $\mathrm{GmbH}$, Germany, software version 1.14r01). Specifically, the following parameters were recorded and analyzed: anterior $\left(\mathrm{r}_{1 \mathrm{c}}\right)$ and posterior corneal radius $\left(\mathrm{r}_{2 \mathrm{c}}\right)$ in the central $3 \mathrm{~mm}$ corneal area, anterior (ACA) and posterior corneal astigmatism (PCA) in the central $3 \mathrm{~mm}$ corneal area, anterior and posterior corneal asphericity (QA and $\mathrm{QP})$, and minimum $\left(\mathrm{e}_{\mathrm{cmin}}\right)$ and central corneal thickness $\left(\mathrm{e}_{\text {ccentral }}\right)$. Keratometric corneal power $\left(\mathrm{P}_{\mathrm{k}}\right)$ using $\mathrm{n}_{\mathrm{k}}=1.33751$ and Gaussian corneal power $\left(\mathrm{P}_{\mathrm{c}}^{\text {Gauss }}\right.$ ) based on Gaussian optics in paraxial approximation ${ }^{1}$ were calculated. The True Net Power was also obtained, which is the Pentacam system corneal power calculated by using the Gaussian equation $\left(P_{c}^{\text {Gauss }}\right)$ with the Gullstrand eye model neglecting the corneal thickness $\left(e_{c}\right)$.

An adjusted keratometric index of refraction $\left(\mathrm{n}_{\text {kadj }}\right)$ was considered for the calculation of an adjusted keratometric corneal power ( $\left.\mathrm{P}_{\text {kadj }}\right)$ as follows: ${ }^{2}$

$$
\mathrm{P}_{\text {kadj }}=\left(\mathrm{n}_{\text {kadj }}-1\right) / \mathrm{r}_{1 \mathrm{c}}(1)
$$

This $n_{\text {kadj }}$ allows the estimation of corneal power using the keratometric approach (the cornea as an only optical surface) but minimizing the errors associated to this approach. The most appropriate value of $n_{\text {kadj }}$ to use in a specific keratoconus cornea should be calculated using a mathematical linear relationship dependent on $\mathrm{r}_{1 \mathrm{c}^{\prime}}$ as shown in Table 1. ${ }^{2}$ Eight different linear expressions have been defined and validated for different interval of curvature of the anterior corneal surface (Table 1). ${ }^{2}$

Besides the calculation of $P_{\text {kadj }}$ all cases included in the study were classified according to five different classification systems: Alió-Shabayek, ${ }^{6}$ Amsler-Krumeich, ${ }^{6}$ Rabinowitz-McDonnell, ${ }^{7}$ collaborative longitudinal evaluation of keratoconus (CLEK), ${ }^{12}$ and McMahon ${ }^{13}$ classification systems (Table 2). The specific details of such classification or grading systems for keratoconus are summarized in Table 2.

Differences in the results of such classifications using $\mathrm{P}_{\mathrm{k}}, \mathrm{P}_{\mathrm{c}}^{\text {Gauss }}$ and $\mathrm{P}_{\text {kadj }}$ were analyzed and discussed in detail.

\section{RESULTS}

This study comprised 44 eyes of 27 patients with keratoconus [12 women (44.4\%) and 15 men (55.6\%) with a mean age of 40.8 years \pm 12.8 , range from 14 to 73 years]. The sample comprised 24 left eyes (54.5\%) and 20 right eyes (45.5\%).

Table 1: $n_{\text {kadj }}$ algorithms developed using the Gullstrand eye model for different $r_{1 c}$ and/or $k$ intervals. Likewise, the corresponding theoretical ranges for $n_{\text {kadj }}, P_{\text {kadj }}, P_{c}^{\text {Gauss }}$ and differences $\left(\Delta P_{c}\right)$ between $P_{\text {kadj }}$ and $P_{c}^{\text {Gauss }}$ are also shown. Minimum and maximum $n_{\text {kadj }}$, $P_{\text {kadj }}$ and $P_{c}^{\text {Gauss }}$ values are bolded in the table

\begin{tabular}{lllllll}
\hline$r_{1 \mathrm{c}}(\mathrm{mm})$ & {$\left[k_{\min }, k_{\max }\right]$} & $n_{\text {kadj }}$ Algorithm & $n_{\text {kadj }}$ & $P_{c}^{\text {Gauss }}(D)$ & $P_{\text {kadj }}(D)$ & $\Delta P_{c}(D)$ \\
\hline$[4.2,4.7]$ & {$[1.20,1.52]$} & $-0.01217_{\mathrm{r} 1 \mathrm{c}}+1.3777$ & {$[1.3205,1.3266]$} & {$[67.5,78.5]$} & {$[68.2,77.8]$} & {$[-0.7,0.7]$} \\
{$[4.8,5.6]$} & {$[1.17,1.56]$} & $-0.01043_{\mathrm{r} 1 \mathrm{c}}+1.3774$ & {$[1.3190,1.3273]$} & {$[56.3,68.6]$} & {$[57.0,68,2]$} & {$[-0.7,0.7]$} \\
{$[5.7,6.2]$} & {$[1.21,1.55]$} & $-0.00926_{\mathrm{r} 1 \mathrm{c}}+1.3773$ & {$[1.3199,1.3245]$} & {$[50.9,57,7]$} & {$[51.6,56.9]$} & {$[-0.7,0.7]$} \\
{$[6.3,6.4]$} & {$[1.05,1.31]$} & $-0.00741_{\mathrm{r} 1 \mathrm{c}}+1.3770$ & {$[1.3296,1.3303]$} & {$[50.8,53.2]$} & {$[51.5,52.4]$} & {$[-0.7,0.7]$} \\
{$[6.5,6.8]$} & {$[1.14,1.45]$} & $-0.00792_{\mathrm{r} 1 \mathrm{c}}+1.3771$ & {$[1.3243,1.3266]$} & {$[47.0,51.0]$} & {$[47.4,50.2]$} & {$[-0.7,0.7]$} \\
{$[6.9,7.5]$} & {$[1.03,1.39]$} & $-0.00669_{\mathrm{r} 1 \mathrm{c}}+1.3767$ & {$[1.3266,1.3306]$} & {$[42.9,48.6]$} & {$[43.8,47.9]$} & {$[-0.7,0.7]$} \\
{$[7.6,7.8]$} & {$[1.09,1.39]$} & $-0.00643_{\mathrm{r} 1 \mathrm{c}}+1.3767$ & {$[1.3266,1.3279]$} & {$[41.2,43.9]$} & {$[41,9,43,1]$} & {$[-0.7,0.7]$} \\
{$[7.9,8.5]$} & {$[0.96,1.35]$} & $-0.00561_{\mathrm{r} 1 \mathrm{c}}+1.3768$ & {$[1.3291,1.3324]$} & {$[38.0,42,8]$} & {$[38.7,42.1]$} & {$[-0.7,0.7]$} \\
\hline
\end{tabular}


Table 2: Keratoconus classification or grading systems used

\begin{tabular}{|c|c|c|c|c|}
\hline Classification & Stage I & Stage II & Stage III & Stage IV \\
\hline Alio-Shabayek $^{6}$ & $\begin{array}{l}P_{k}<48 D \\
\text { RMS (1.5 to } 2.5) \mu \mathrm{m}\end{array}$ & $\begin{array}{l}P_{k}>48 D \text { to } \leq 53 D \\
R M S>2.5 \text { to } \leq 3.5 \mu \mathrm{m} \\
e_{c \min }>400 \mu \mathrm{m}\end{array}$ & $\begin{array}{l}P_{k}>53 D \text { to } \leq 55 D \\
R M S>3.5 \text { to } \leq 4.5 \mu \mathrm{m} \\
e_{c \min }(300 \text { to } 400) \mu \mathrm{m}\end{array}$ & $\begin{array}{l}P_{k}>55 D \\
R M S>4.5 \mu \mathrm{m} \\
e_{c \min }<200 \mu \mathrm{m}\end{array}$ \\
\hline Amsler-Krumeich ${ }^{6}$ & $\begin{array}{l}\text { Myopia and Astig. }<5 D \\
P_{k}<48 D\end{array}$ & $\begin{array}{l}\text { Myopia and Astig. from } \\
5 D \text { to } 8 D \\
P_{k}<53 D \\
e_{c \min }>400 \mu \mathrm{m}\end{array}$ & $\begin{array}{l}\text { Myopia and Astig. from } \\
8 D \text { to } 10 D \\
P_{k}>53 D \\
e_{c \min }(300 \text { to } 400) \mu \mathrm{m}\end{array}$ & $\begin{array}{l}P_{k}>55 D \\
e_{c \min }<200 \mu m\end{array}$ \\
\hline Rabinowitz-McDonnell $^{7}$ & $\begin{array}{l}\text { No KC } \\
\text { Sim K } \leq 47.2 \mathrm{D} \\
\mathrm{I}-\mathrm{S}<1.4\end{array}$ & $\begin{array}{l}\text { KC suspect } \\
\text { Sim K (47.2 to } 48.7) \mathrm{D} \\
\text { I-S [1.4 to } 1.9]\end{array}$ & $\begin{array}{l}\text { KC } \\
\text { Sim } K>48.7 D \\
\mathrm{I}-\mathrm{S}>1.9\end{array}$ & \\
\hline CLEK $^{12}$ & $\begin{array}{l}\text { Mild KC } \\
\mathrm{P}_{\mathrm{k}}<45 \mathrm{D}\end{array}$ & $\begin{array}{l}\text { Moderate } \mathrm{KC} \\
\mathrm{P}_{\mathrm{k}} \geq 45 \text { to } \leq 52 \mathrm{D}\end{array}$ & $\begin{array}{l}\text { Severe } K C \\
P_{k}>52 D\end{array}$ & \\
\hline McMahon $^{13}$ & $\begin{array}{l}\text { KC Atypical } \\
47.75 \mathrm{D}<\mathrm{P}_{\mathrm{K}} \leq 48 \mathrm{D} \\
\text { suspect } K C \\
48 \mathrm{D}<\mathrm{P}_{\mathrm{k}} \leq 49 \mathrm{D}\end{array}$ & $\begin{array}{l}\text { Mild KC } \\
49 \mathrm{D}<\mathrm{P}_{\mathrm{k}} \leq 52 \mathrm{D}\end{array}$ & $\begin{array}{l}\text { Moderate KC } \\
52 \mathrm{D}<\mathrm{P}_{\mathrm{k}} \leq 56 \mathrm{D}\end{array}$ & $\begin{array}{l}\text { Severe KC } \\
P_{k}>56.01 D\end{array}$ \\
\hline
\end{tabular}

Astig: astigmatism; $P_{k}$ : central corneal power; $e_{c m i n}$ : minimum central corneal thickness; RMS: Root mean square; KC: keratoconus; Sim K: simulated keratometry

\section{Alio-Shabayek and Amsler-Krumeich Grading Systems}

Alio-Shabayek and Amsler-Krumeich grading systems consider similar $\mathrm{P}_{\mathrm{k}}$ range values for keratoconus classification. Besides this, these classifications consider other parameters, such as the root mean square (RMS) value for coma-like aberrations, the myopic refractive error, the magnitude of astigmatism or corneal thickness. Considering only the corneal power value, 29 keratoconus eyes of our sample were classified in stage I if $\mathrm{P}_{\mathrm{k}(1.3375)}$ was used, whereas 31 keratoconus were classified in stage I if $\mathrm{P}_{\text {kadj }}$ was used, with an overestimation of $\mathrm{P}_{\mathrm{k}(1.3375)}$ between 0.60 and $1.40 \mathrm{D}$ (Table 3). Concerning stage II, 11 keratoconus cases were included in it if $\mathrm{P}_{\mathrm{k}(1.3375)}$ was used and 12 if $P_{\text {kadj }}$ was considered. This difference in the number of eyes graded as stage II was due to an overestimation of corneal power in some cases with the classical keratometric approach (between 1.10 and $1.90 \mathrm{D}$ ). In one case, an overestimation of $2.30 \mathrm{D}$ was found when $\mathrm{P}_{\mathrm{k}(1.3375)}$ and $\mathrm{P}_{\mathrm{c}}^{\text {Gauss }}$ were compared. However, with both corneal power values, $\mathrm{P}_{\mathrm{k}(1.3375)}$ and $\mathrm{P}_{\mathrm{c}}^{\text {Gauss }}$, this case was classified as stage II (Table 3).

There were three keratoconus eyes graded as Stage III when $\mathrm{P}_{\mathrm{k}(1.3375)}$ was used, but all of them were included

Table 3: Patients classified in different keratoconus stages following the Alio-Shabayek classification method and considering the adjusted and classical keratometric corneal power

\begin{tabular}{lllll}
\hline & $n_{1} P_{k(1.3375)}$ & $\%$ & $n_{2} P_{\text {kadj }}$ & $\%$ \\
\hline Stage I & 29 & 65.9 & 31 & 70.5 \\
Stage II & 11 & 25 & 12 & 27.3 \\
Stage III & 3 & 6.8 & 0 & 0 \\
Stage IV & 1 & 2.3 & 1 & 2.3 \\
\hline
\end{tabular}

$\mathrm{n}_{1}$ : $\mathrm{KC}$ cases using $\mathrm{P}_{\mathrm{k}(1.3375)}$; \%: total percentage of $\mathrm{KC}$ cases in each stage; $n_{2}: K C$ cases using $P_{\text {kadj }}$ in stage II when $P_{\text {kadj }}$ was considered (Table 3). This was due to an overestimation in these 3 cases of corneal power with the classical keratometric approach of $1.1 \mathrm{D}$. Only 1 keratoconus eye was classified as stage IV with both $\mathrm{P}_{\mathrm{k}(1.3375)}$ and $\mathrm{P}_{\text {kadj }}$ in spite of the presence of an overestimation of $2.3 \mathrm{D}$ of corneal power when the classical keratometric approach was used (Table 3). It should be remarked that the same results were obtained using $\mathrm{P}_{\text {kadj' }}$ True Net Power or $\mathrm{P}_{\mathrm{c}}^{\text {Gauss }}$.

\section{Rabinowitz-McDonnell Classification System}

The main parameters of this classification system are topographic, I-S and Sim K values. Considering only the corneal power calculation, we found in our series 27 cases classified as normal if $P_{k(1.3375)}$ was used and 31 cases if $\mathrm{P}_{\text {kadj }}$ was used, with an overestimation of corneal power with $\mathrm{P}_{\mathrm{k}(1.3375)}$ between 0.60 and $1.40 \mathrm{D}$ (Table 4). Likewise, in our series, 4 cases of keratoconus suspect were found if $\mathrm{P}_{\mathrm{k}(1.3375)}$ was used. In contrast, if $\mathrm{P}_{\mathrm{kadj}}$ was considered, these 4 cases were reclassified as normal cases (Table 4). This difference was due to an overestimation of corneal power with $P_{k(1.3375)}$ in these four cases that ranged between 1.10 and 1.20 D. Finally, a total 13 eyes were classified as keratoconus if $\mathrm{P}_{\mathrm{k}(1.3375)}$ was used and 8 if $\mathrm{P}_{\text {kadj }}$ was considered. A total of 5 cases (38.5\%) were

Table 4: Patients classified in different keratoconus stages following the Rabinowitz-McDonnell classification method

\begin{tabular}{lllll}
\hline & $n_{1}$ & & $n_{2}$ & \\
& $P_{k(1.3375)}$ & $\%$ & $P_{\text {kadj }}$ & $\%$ \\
\hline Normal & 27 & 61.4 & 31 & 70.4 \\
Suspect & 4 & 9.1 & 5 & 11.4 \\
Keratoconus & 13 & 29.5 & 8 & 18.2 \\
\hline
\end{tabular}

$n_{1}$ : KC cases using $P_{k(1.3375)}$; \%: total percentage of $K C$ cases in each stage; $n_{2}$ : KC cases using $P_{\text {kadj }}$ 
reclassified as keratoconus suspect when $\mathrm{P}_{\text {kadj }}$ was used due to an overestimation in these five cases of corneal power with $P_{k(1.3375)}$ (between 1.10 and 2.30 D, Table 4).

If $P_{c}^{\text {Gauss }}$ was used, one case initially classified as normal was reclassified as keratoconus suspect, although the difference between $\mathrm{P}_{\mathrm{c}}^{\text {Gauss }}$ and $\mathrm{P}_{\text {kadj }}$ was only of -0.10 D. Likewise, 2 keratoconus suspect eyes were reclassified as keratoconus if True Net Power or $\mathrm{P}_{\mathrm{c}}{ }^{\text {Gauss }}$ were used. It should be considered that differences between $P_{\text {kadj }}$ and $\mathrm{P}_{\mathrm{c}}$ Gauss were not clinically significant, with $\mathrm{P}_{\text {kadj }}$ underestimating $\mathrm{P}_{\mathrm{c}}$ Gauss between 0.30 and $0.50 \mathrm{D}$. In contrast, differences between $\mathrm{P}_{\text {kadj }}$ and True Net Power were clinically significant, with an overestimation between 0.50 and $0.60 \mathrm{D}$.

\section{Collaborative Longitudinal Evaluation of Keratoconus Grading System}

With the CLEK classification, 17 keratoconus were classified as mild KC if $\mathrm{P}_{\mathrm{k}(1.3375)}$ was used, and 24 if $\mathrm{P}_{\text {kadj }}$ was considered. This difference in grading was due to the overestimation of corneal power by $\mathrm{P}_{\mathrm{k}(1.3375)}$ in a range between 0.60 and $1.30 \mathrm{D}$ (Table 5). A total of 23 eyes were classified as Moderate $\mathrm{KC}$ if $\mathrm{P}_{\mathrm{k}(1.3375)}$ was used and 16 if $\mathrm{P}_{\text {kadj }}$ was considered, with 7 cases $(30.4 \%)$ being reclassified as mild KC. This difference in grading was also due to the overestimation of corneal power by $\mathrm{P}_{\mathrm{k}(1.3375)}$ that in these 7 cases ranged between 1.40 and $1.80 \mathrm{D}$ (Table 5). Four cases were classified as severe KC using $\mathrm{P}_{\mathrm{k}(1.3375)}$ and $\mathrm{P}_{\text {kadj }}$, in spite of the overestimation in such cases of corneal power by the classical keratometric approach that ranged between 1.10 and $2.30 \mathrm{D}$ (Table 5). All these results were the same compared with $P_{\text {kadj }}$ if True Net Power was used. However, when $\mathrm{P}_{\mathrm{c}}^{\text {Gauss }}$ was used, 2 mild KC cases were reclassified as moderate KC compared to $\mathrm{P}_{\mathrm{kadj}}$, although differences between corneal power estimations were not clinically relevant (0.1-0.2 D).

\section{McMahon Grading System}

McMahon grading system is based on the combined analysis of topographic patterns, best spectacle corrected acuity, steepening and flat keratometry reading and clinical keratoconus corneal signs. Considering the value of corneal power, 29 cases were classified as normal

Table 5: Patients classified in different keratoconus stages following CLEK classification method

\begin{tabular}{lllll}
\hline & $n_{1}$ & & $n_{2}$ & \\
& $P_{k(1.3375)}$ & $\%$ & $P_{\text {kadj }}$ & $\%$ \\
\hline Mild & 17 & 38.6 & 24 & 54.5 \\
Moderate & 23 & 52.3 & 16 & 36.4 \\
Severe & 4 & 9.1 & 4 & 9.1 \\
\hline
\end{tabular}

$n_{1}$ : KC cases using $P_{k(1.3375)}$; \%: total percentage of $K C$ cases in each stage, $n_{2}$ : KC cases using $P_{\text {kadj }}$
Table 6: Patients classified in different keratoconus stages following the McMahon classification method

\begin{tabular}{lllll}
\hline & $n_{1}$ & & $n_{2}$ & \\
& $P_{k(1.3375)}$ & $\%$ & $P_{\text {kadj }}$ & $\%$ \\
\hline Normal & 29 & 65.9 & 31 & 70.5 \\
Suspect & 2 & 4.5 & 5 & 11.3 \\
Mild & 9 & 20.5 & 4 & 9.1 \\
Moderate & 3 & 6.8 & 3 & 6.8 \\
Severe & 1 & 2.3 & 1 & 2.3 \\
\hline
\end{tabular}

$n_{1}$ : KC cases using $P_{k(1.3375)}$; \%: total percentage of $K C$ cases in each stage; $n_{2}: K C$ cases using $P_{\text {kadj }}$

if $\mathrm{P}_{\mathrm{k}(1.3375)}$ or $\mathrm{P}_{\text {kadj }}$ were used indistinctly, even though $\mathrm{P}_{\mathrm{k}(1.3375)}$ overestimated $\mathrm{P}_{\text {kadj }}$ between 0.60 and $1.40 \mathrm{D}$. A total of two suspect $K C$ were found if $P_{k(1.3375)}$ was used, while if $P_{\text {kadj }}$ was considered these two cases were considered as normal due to the overestimation of corneal power by $\mathrm{P}_{\mathrm{k}(1.3375)}$ in theses two cases of 1.1 D (Table 6). Nine cases were classified as mild $\mathrm{KC}$ if $\mathrm{P}_{\mathrm{k}(1.3375)}$ was used and five if $\mathrm{P}_{\text {kadj }}$ was considered. This difference in grading was due to an overestimation of corneal power by the classical keratometric approach between 1.7 and 1.9 D (Table 6). Moderate KC were observed in 3 cases and severe $K C$ in 1 case using $P_{k(1.3375)}$ and $P_{\text {kadj }}$ although the overestimation of corneal power by $\mathrm{P}_{\mathrm{k}(1.3375)}$ in these three moderate cases was of $1.10 \mathrm{D}$ and in the severe case was of 2.3 D (Table 6).

If $\mathrm{P}_{\mathrm{c}}^{\text {Gauss }}$ was used, two cases classified as suspect were reclassified as mild, with a difference between $\mathrm{P}_{\mathrm{c}}^{\text {Gauss }}$ and $\mathrm{P}_{\text {kadj }}$ ranging from -0.50 to $-0.6 \mathrm{D}$. Also, one mild $\mathrm{KC}$ eye was reclassified as suspect, with $0.6 \mathrm{D}$ of difference between $\mathrm{P}_{\mathrm{c}}^{\text {Gauss }}$ and $\mathrm{P}_{\text {kadj. }}$. Finally, three moderate $\mathrm{KC}$ were reclassified as mild grade, with differences between the Gaussian and the adjusted keratometric approach ranging from 0.40 to $0.70 \mathrm{D}$. If True Net Power was used and compared with $\mathrm{P}_{\text {kadj }}$ one suspect $\mathrm{KC}$ was classified as mild $\left(-0.50 \mathrm{D}\right.$ of difference between $\mathrm{P}_{\text {kadj }}$ and True Net Power), and one mild $\mathrm{KC}$ was classified as suspect ( $0.70 \mathrm{D}$ of difference between $P_{\text {kadj }}$ and True Net Power). Finally, three moderate KC were classified as mild if True Net Power was used, with differences between the adjusted keratometric approach and True Net Power ranging from 0.6 to $0.9 \mathrm{D}$.

\section{DISCUSSION}

In the current study, we have tried to confirm if the use of the adjusted keratometric corneal power $\left(\mathrm{P}_{\text {kadj }}\right)$, a concept developed by our research group in previous studies, ${ }^{1,2}$ could affect significantly the grading of keratoconus severity using classification systems based on the use of corneal power. For such purpose, we have compared the result obtained with the adjusted keratometric approach with that obtained using the classical keratometric 
readings $\left(\mathrm{P}_{\mathrm{k}(1.3375)}\right)$. It should be considered that the exact corneal power calculation in paraxial optics can only be obtained by calculating $P_{c}^{\text {Gauss }}$ and using the curvature of both corneal surfaces $\left(\mathrm{r}_{1 \mathrm{c}}\right.$ and $\mathrm{r}_{2 \mathrm{c}}$ ). However, devices providing curvature measurements of both corneal surfaces are not always available in clinical practice, and the keratometric corneal power $\left(\mathrm{P}_{\mathrm{k}}\right)$ is used as an estimation of corneal power.

Our results show that with the use of $\mathrm{P}_{\text {kadj }}$ several keratoconus cases would be reclassified. Specifically, 6 keratoconus (13.6\%) cases would be reclassified using $\mathrm{P}_{\text {kadj }}$ and the Alió-Shabayek or the Amsler-Krumeich grading systems, with the same reclassifications if the True Net Power or $\mathrm{P}_{\mathrm{c}}^{\text {Gauss }}$ were considered. With the Rabinowitz-McDonnell grading system, 10 keratoconus (22.7 $\%)$ were reclassified using $\mathrm{P}_{\text {kadj, }}$ with only differences in three and two cases when a reclassification was done using $P_{c}^{\text {Gauss }}$ and True Net Power, respectively. Although differences between $P_{\text {kadj }}$ and $P_{c}^{\text {Gauss }}$ in those cases were not clinically relevant $(0.1,0.3$ and $0.5 \mathrm{D})$, differences between $\mathrm{P}_{\text {kadj }}$ and True Net Power were considerable $(0.5$ and $0.6 \mathrm{D})$. Concerning the CLEK grading system, 14 keratoconus $(31.8 \%)$ cases were reclassified using $\mathrm{P}_{\text {kadj }}$, with only two cases differing if $\mathrm{P}_{\mathrm{c}}^{\text {Gauss }}$ was used, although differences between $P_{\text {kadj }}$ and $P_{c}^{\text {Gauss }}$ were not clinically relevant (0.1 and $0.2 \mathrm{D})$. Finally, 10 keratoconus cases $(22.7 \%)$ were reclassified using the McMahon classification system if $\mathrm{P}_{\text {kadj }}$ was used and compared with $P_{k(1.3375)}$. If $P_{c}^{\text {Gauss }}$ was used, six cases differed from the use of $\mathrm{P}_{\text {kadj }}$, with differences between -0.6 and $0.7 \mathrm{D}$, and five if the True Net Power was used, with differences between -0.5 and $0.9 \mathrm{D}$.

As demonstrated in previous studies, ${ }^{1,2}$ if a limit value of $P_{k(1.3375)}$ ss $<48$ D is considered as a criterion for defining an incipient keratoconus, an error is being assumed that may range between -0.1 and $2.10 \mathrm{D}$ depending on $\mathrm{r}_{1 \mathrm{c}}$ and $\mathrm{r}_{2 \mathrm{c}}$ combinations, when we compared $\mathrm{P}_{\mathrm{k}(1.3375)}$ with $\mathrm{P}_{\mathrm{c}}^{\text {Gauss. }}$. To consider $\mathrm{P}_{\mathrm{k}(1.3375)}$ limits for moderate keratoconus classification between 48 and $55 \mathrm{D}$ may lead to overestimations of real corneal power between 0.3 and 3.5 D. ${ }^{1,2}$ Likewise, the use of a $P_{k(1.3375)}$ value higher than $55 \mathrm{D}$ as a limit for defining a severe keratoconus would be associated to potential overestimations between 1.8 and $4.0 \mathrm{D}^{1,2}$ These errors in using the classical keratometric powers as valid estimators of corneal power in keratoconus are the reasons for the findings of the current study. When $\mathrm{P}_{\mathrm{k}(1.3375)}$ and $\mathrm{P}_{\text {kadj }}$ were compared, differences up to $13.6 \%$ in the type of grading of keratoconus cases was found when the Alió-Shabayek or the Amsler-Krumeich grading systems were used. With the RabinowitzMcDonnell and McMahon classification systems differences up to $22.7 \%$ were obtained in the type of grading of our keratoconus cases, and up to $31.8 \%$ when the CLEK classification system was used. As may be expected, errors in classification were more frequent when corneal power values approached to the limits established by each author between grades, being the most common errors those associated to the grading between moderate and severe keratoconus. A relevant finding that should be remarked is that $100 \%$ of reclassified cases using $\mathrm{P}_{\text {kadj }}$ were done in a less severe stage, indicating that the use of classical keratometry may lead to the classification of a cornea as keratoconus, being a normal case. In general, the results obtained using $\mathrm{P}_{\text {kadj' }} \mathrm{P}_{\mathrm{c}}^{\text {Gauss }}$ or the True Net Power were equivalent. Differences between $P_{\text {kadj }}$ and $\mathrm{P}_{\mathrm{c}}^{\text {Gauss }}$ never exceeded $\pm 0.7 \mathrm{D}$ as predicted in our previous articles, ${ }^{1,2}$ with only one case showing a difference of $0.9 \mathrm{D}$ between $\mathrm{P}_{\text {kadj }}$ and True Net Power.

\section{CONCLUSION}

The use of classical keratometric corneal power may lead to incorrect grading of the severity of keratoconus, with a trend to more severe grading. The use of an adjusted keratometric corneal power calculated using a variable refractive index dependent on $\mathrm{r}_{1 \mathrm{c}}$ seems to be a useful method to minimize this error when a device measuring both corneal surfaces is not available in clinical practice. If it is available, grading of keratoconus should be performed considering $\mathrm{P}_{\mathrm{c}}^{\text {Gauss }}$ or True Net Power.

\section{REFERENCES}

1. Piñero DP, Camps VJ, Caravaca-Arens E, Pérez-Cambrodí RJ, Artola A. Estimation of the central corneal power in keratoconus: theoretical and clinical assessment of the error of the keratometric approach. Cornea 2014;33(3):274-279.

2. Camps VJ, Piñero DP, Caravaca-Arens E, de Fez D, PérezCambrodí RJ, Artola A. New approach for correction of error associated with keratometric estimation of corneal power in keratoconus. Cornea 2014;33(9):960-967.

3. Piñero DP, Nieto JC, Lopez-Miguel A. Characterization of corneal structure in keratoconus. J Cataract Refract Surg 2012;38(12):2167-2183.

4. Maeda N, Klyce SD, Smolek MK, Thompson HW. Automated keratoconus screening with corneal topography analysis. Invest Ophthalmol Vis Sci 1994;35(6):2749-2757.

5. Piñero DP, Alio JL, Aleson A, Escaf M, Miranda M. Pentacam posterior and anterior corneal aberrations in normal and keratoconic eyes. Clin Exp Òptom 2009;92(3):297-303.

6. Alio JL, Shabayek MH. Corneal higher order aberrations: a method to grade keratoconus. J Refract Surg 2006;22:539-545.

7. Rabinowitz YS, McDonnell PJ. Computer-assisted corneal topography in keratoconus. Refract Corneal Surg 1989;5(6): 400-408.

8. Rabinowitz YS. Videokeratographic indices to aid in screening for keratoconus. J Refract Surg 1995;11(5):371-379.

9. Rabinowitz YS. Keratoconus. Surv Ophthalmol 1998 Jan-Feb; 42(4):297-319. 
10. Twa MD, Parthasarathy S, Roberts C, Mahmoud AM, Raasch TW, Bullimore MA. Automated decision tree classification of corneal shape. Optom Vis Sci 2005;82(12):1038-1046.

11. Rabinowitz YS, Rasheed K. KISA\% index: a quantitative videokeratography algorithm embodying minimal topographic criteria for diagnosing keratoconus. J Cataract Refract Surg 1999 Oct;25(10):1327-1335.

12. Wagner H, Barr JT, Zadnik K. Collaborative longitudinal evaluation of keratoconus study: methods and findings to date. Cont Lens Anterior Eye 2007;30(4):223-232.
13. McMahon TT, Szczotka-Flynn L, Barr JT, Anderson RJ, Slayhter ME, Lass JH, Jyengar SK. CLEK study group: a new method for grading the severity of keratoconus-the keratoconus severity score. Cornea 2006 Aug;25(7):794-800.

14. Gore DM, Shortt AJ, Allan BD. New clinical pathways for keratoconus. Eye (Lond) 2013 Mar;27(3):329-339.

15. Pinero DP, Alio JL, Aleson A, Escaf Vergara M, Miranda M. Corneal volume, pachymetry, and correlation of anterior and posterior corneal shape in subclinical and different stages of clinical keratoconus. J Cataract Refract Surg 2010 May;36(5):814-825. 